\title{
PERANCANGAN APLIKASI M-LEARNING SENI BUDAYA DAN KETERAMPILAN KELAS 5 BERBASIS ANDROID
}

\author{
Nur Apriani $^{1}$, Aulia Paramita ${ }^{2}$, Shinta Dwi Handayani ${ }^{3}$ \\ Program Studi Informatika, Fakultas Teknik dan Ilmu Komputer, Universitas Indraprasta PGRI \\ Jalan Raya Tengah No 80, Kelurahan Gedong, Pasar Rebo, Jakarta Timur \\ Nurapriani69@gmail.com, Aulia.pps@gmail.com², shintadh@gmail.com ${ }^{3}$
}

\begin{abstract}
Abstrak
Mata pelajaran Seni Budaya dan Keterampilan sering juga disebut SBK dianggap mata pelajaran yang kurang diminati oleh murid kelas 5 di MI Sirojul Athfal karena siswa lebih memperhatikan mata pelajaran produktif seperti matematika. Selain Kurang diminati oleh siswa ternyata media ajar yang digunakan oleh guru dalam pembelajaran kurang efektif, karena guru masih mengandalkan buku teks dalam penyampaian materi. Sehingga, murid-murid kurang bisa memvisualisasikan pelajaran SBK dengan baik. Tujuan penelitian adalah untuk memberikan solusi kepada tempat penelitian terkait menerapkan media digital dalam proses pembelajaran SBK dengan membuat suatu aplikasi dan mempermudah dalam membuat penilaian terhadap murid-murid yang telah berhasil mengerjakan evaluasi. Metode penelitian yang digunakan dalam perancangan aplikasi $M$-Learning yaitu metode SDLC (System Development Life Cycle) yaitu pendekatan yang bertahap untuk melakukan analisa dan membangun suatu rancangan sistem dengan menggunakan siklus yang lebih spesifik terhadap kegiatan pengguna. Sehingga peneliti dapat menarik kesimpulan bahwa pihak sekolah dan murid kelas 5 diberi kemudahan dalam melaksanakan proses pembelajaran dengan mengimplementasikan media digital atau aplikasi yang telah dirancang dan dibangun dengan tersistem dan terstruktur, sehingga tingkat kerusakan dalam proses pembelajaran menggunakan media cetak dapat teratasi. Sekolah juga dapat dipermudah dalam membuat penilaian dari hasil evaluasi kepada murid-murid yang telah mengerjakan evaluasi melalui aplikasi.
\end{abstract}

Kata Kunci: M-Learning, Android, Seni Budaya, Keterampilan

\begin{abstract}
Arts culture and skills are often called SBK is considered subjects that are not in demand by grade 5 students at MI Sirojul Athfal because students pay more attention to productive subjects such as mathematics. In addition to less interest by students, the teaching media used by teachers in learning is less effective, because the teacher still relies on textbooks in delivering material. Thus, students are less able to visualize SBK lessons well. The aim of the research is to provide solutions to the research place to apply digital media to the SBK learning process by creating an application and making it easier to make an assessment of the students who have succeeded Evaluation. The research method used in the design of M-Learning application is SDLC (System Development Life Cycle) method which is a gradual approach to analyze and build a system design using a more specific to user activity. So that researchers can draw conclusions that the school and the 5th grade students are provided with ease in carrying out the learning process by implementing digital media or applications that have been designed and built with the system and the degree of damage in the learning process using print media can be resolved. Schools can also be made easy to make assessments of evaluation results to students who have done evaluation through the application.
\end{abstract}

Keywords: M-Learning, Android, Cultural Arts, Skills

\section{PENDAHULUAN}

Perkembangan teknologi saat ini sangat pesat dan hampir menyeluruh di segala bidang. Salah satunya adalah berkembangnya teknologi seluler yang kini telah menjelma menjadi sebuah telepon pintar atau smartphone yang dapat melakukan banyak hal, mulai untuk berkomunikasi, sarana hiburan, media sosial, dan sebagai aplikasi pembelajaran. Salah satu perkembangan aplikasi pembelajaran adalah dengan menggunakan perangkat bergerak (mobile device) yang biasa dikenal sebagai mobile learning (m-learning).

Pendidikan seni pada umumnya meliputi seni rupa, seni musik, seni tari dan seni drama (seni teater). Sejak awal munculnya pelajaran umum dalam pembelajaran di sekolah, para pendidik seni rupa berjuang agar seni dipertimbangkan secara serius. Sayangnya, mata pelajaran Seni Budaya dan 
Keterampilan atau sering disebut dengan SBK dianggap mata pelajaran yang kurang diminati oleh murid kelas 5 di MI Sirojul Athfal, siswa lebih memperhatikan mata pelajaran produktif seperti matematika. Selain karena Kurang diminati oleh siswa ternyata media ajar yang digunakan oleh guru dalam pembelajaran kurang efektif, karena guru masih mengandalkan buku teks dalam penyampaian materi, sehingga murid-murid kurang bisa memvisualisasikan pelajaran SBK dengan baik.

Bedasarkan latar belakang di atas, maka peneliti tergerak untuk membuat aplikasi belajar yang berbasis Android. Aplikasi ini berfungsi sebagai media penunjang dalam proses belajar yang diharapkan dapat membantu guru dalam proses pembelajaran SBK. Aplikasi ini menggunakan bahasa Indonesia yang dilengkapi dengan tampilan yang menarik minat murid untuk belajar. Peneliti berharap dapat memuat system yang mudah digunakan sehingga bermanfaat bagi murid yang disajikan dalam bentuk penelitian.

Berdasarkan pemaparan latar belakang dan batasan masalah, maka dapat dirumuskan permasalahan yang ada maka peneliti merancang sebuah aplikasi aplikasi m-learning Seni Budaya dan Keterampilan untuk siswa kelas 5 berbasis Android untuk meingkatkan kualitas pembelajaran SBK di MI Sirojul Athfal dan memberikan cara bagaimana mengatasi keterbatasannya media buku SBK kelas 5 di MI Sirojul Athfal. Sesuai dengan permasalahan yang dirumuskan sebelumnya, maka dihasilkan tujuan penelitian yang akan dilakukan untuk merancang dan membangun aplikasi m-learning Seni Budaya dan Keterampilan berbasis Androi, Memberikan media alternatif pembelajaran SBK pada siswa dengan media m-learning. dan mengatasi keterbatasan media buku SBK kelas 5 di MI Sirojul Athfal.

Penelitian ini diharapkan memberi manfaat untuk semua komponen yaitu siswa, guru, sekolah dan peneliti sendiri. Untuk siswa diharapkan dapat meningkatkan sikap positif siswa terhadap pelajaran Seni Budaya dan Keterampilan serta meningkatkan hasil belajar. Guru sebagai masukan bagi mata pelajaran khususnya SBK untuk dijadikan bahan pertimbangan dalam memilih model pembelajaran SBK dengan aplikasi m-learning, sedangkan untuk sekolah diharapkan dapat menjadi salah satu bahan acuan bagi sekolah dalam rangka meningkatkan kualitas proses belajar mengajar khususnya mata pelajaran SBK

\section{PENELITIAN RELEVAN}

Dalam rangka mendapatkan hasil penelitian yang baik, selain melakukan penelitian secara langsung peneliti juga melakukan kajian pustaka. Dari hasil penelitian yang telah dilakukan. Beberapa hasil acuan yang menjadi acuan adalah:

Penelitian dari Tedi Budiman, tahun 2018 yang berjudul "Perancangan Sistem Pembelajaran Mobile (M-Learning) Berbasis Android Pada Materi Bangun Datar Dan Bangun Ruang". Penelitian ini menghasilkan Pembelajaran matematika secara mandiri dapat dilakukan di media mobile, menggunakan media HP atau PD. Program aplikasi m-learning berbasis android pada materi bangun datar dan bangun ruang, dapat memudahkan user dalam mencari materi yang diinginkan.

Penelitian dari Liranti Rahmelina, tahun 2017 yang berjudul "Perancangan Mobile Leraning Berbasis Android Pada Mata Kuliah Sistem Operasi Di STMIK Indonesia Padang". Berdasarkan pembahasan yang dilakukan dalam penelitian, maka dapat disimpulkan bahwa Aplikasi Mobile Learning Mata Kuliah Sistem Operasi membantu Mahasiswa dalam proses pembelajaran, memperkenalkan sistem operasi dan melakukan latihan serta membantu proses pembelajaran yang praktis dan fleksibel yaitu pembelajaran yang bersifat dimanapun dan kapanpun.

\section{METODE PENELITIAN}

Menurut (Arifin, 2012) Pengertian penelitian disebutkan bahwa suatu proses penyelidikan yang ilmiyah melalui pengumpulan, pengolahan, analisis dan penyimpulan data berdasarkan pendekatan, metode, dan teknik tertentu untuk menjawab suatu permasalahan. Metode penelitian sistem yang peneliti gunakan adalah metode SDLC (System Development Life Cycle) menurut (Susanto, 2004)"System Development Life Cycle (SDLC) adalah salah satu metode pengembangan sistem informasi yang popular pada saat sistem informasi pertama kali dikembangkan." Dengan metode ini diharapkan dapat mengetahui kekurangan dari setiap anak yang ada sehingga mempermudah peneliti dalam membuat aplikasi M-Learning SBK untuk anak kelas 5 SD berbasis android. Metode 
pengumpulan data yang dilakukan oleh peneliti untuk mendapatkan data-data informasi untuk mendukung penyempurnaan hasil dari penelitian ini antara lain :

\section{Studi Kepustakaan}

Metode ini merupakan pengumpulan data dengan cara membaca atau mengutip yang berasal dari buku, jurnal, atau tulisan-tulisan lain yang relevan terhadap penelitian. Dari bahan-bahan tersebut diambil teori-teori yang dapat dijadikan landasan untuk menganalisa masalah yang ditemukan dalam penelitian.

\section{Studi Lapangan}

Peneliti mengadakan penelitian terhadap objek dilapangan untuk mengetahui secara langsung proses pembelajaran SBK dikelas. Dalam studi lapangan ini digunakan teknik pengumpulan data antara lain dengan cara :

1. Wawancara

Menurut (Sugiyono, 2013:24) Wawancara merupakan pertemuan dua orang untuk bertukar informasi dan ide melalui tanya jawab, sehingga dapat dikonstruksikan makna dalam suatu topin tertentu. Peneliti melakukan interview kepada guru mata pelajaran SBK sesuai dengan kebutuhan data yang akan diperlukan untuk kelengkapan data.

2. Observasi

Menurut (Ladjamudin, 2014:44) Untuk mendapatkan gambaran yang jelas mengenai pelaksanaan sistem yang berjalan serta mencari dan mengumpulkan data yang dibutuhkan langsung dari sumbernya yaitu dengan pengamatan langsung terhadap penyeleksian news untuk melengkapi wawancara. Dalam hal observasi, peneliti menggunakan metode pengamatan secara langsung terhadap pengolahan data untuk mendapatkan data yang dibutuhkan. Observasi dilakukan setelah wawancara untuk menguji kebenaran terhadap data yang diperoleh sehingga dapat membantu proses analisa.

3. Percobaan

Melakukan percobaan setelah rancangan dan modul aplikasi dibuat, sehingga dapat mengetahui prinsip dasar dan cara kerja.

\section{HASIL DAN PEMBAHASAN}

Masalah yang dihadapi dalam membangun aplikasi M-Learning ini adalah bagaimana merancang aplikasi yang mampu membantu meningkatkan kualitas pembelajaran SBK untuk siswa kelas 5 serta mengatasi keterbatasannya media buku SBK kelas 5 di MI Sirojul Athfal. Aplikasi M-Learning merupakan salah satu alternatif pembelajaran bagi siswa dengan memanfaatkan telepon genggam sebagai sarana belajarnya. Pembelajaran pada dasarnya menggunakan media buku yang memiliki keterbatasan seperti mudah usang atau rusak, harganya cenderung mahal, tidak ramah lingkungan karena buku menggunakan kertas . Untuk itu perlu dibuat aplikasi M-Learning yang dapat digunakan selama pembelajaran SBK kelas 5, dalam hal ini di dalam sebuah telepon genggam yang telah memiliki dukungan Operating System Android. 


\section{Flowchart Dan Unified Modeling Language (UML)}

\section{Flowchart}

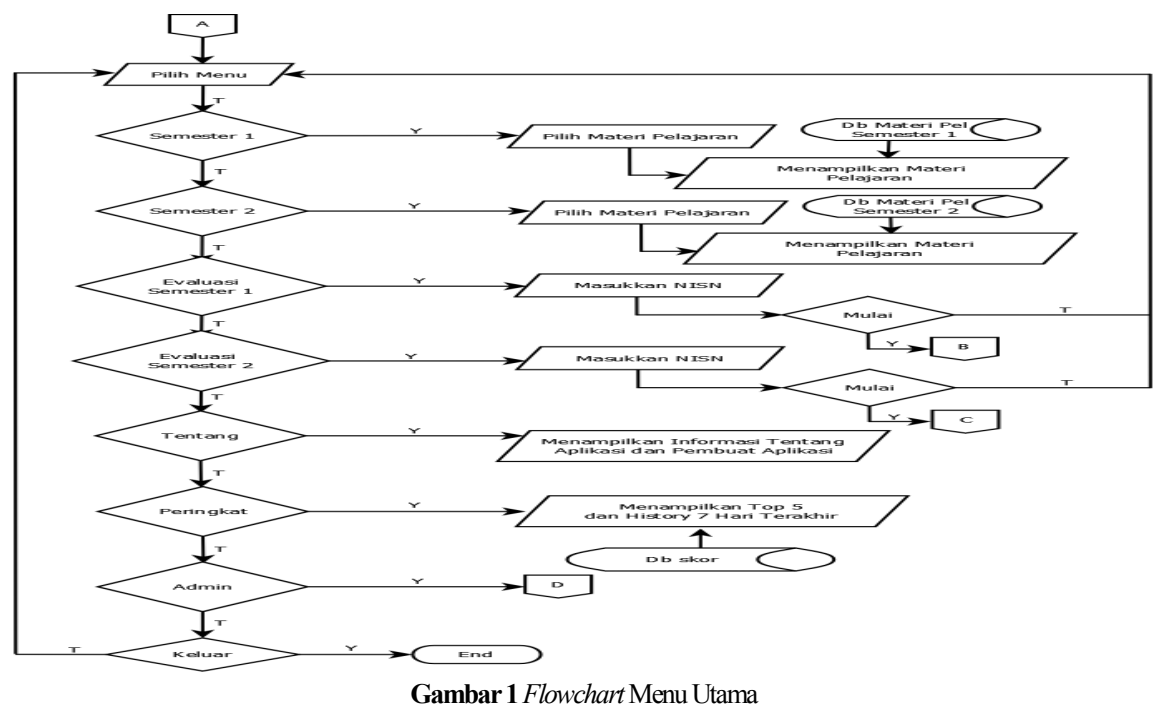

Unified Modeling Language (UML)

Usecase Diagram
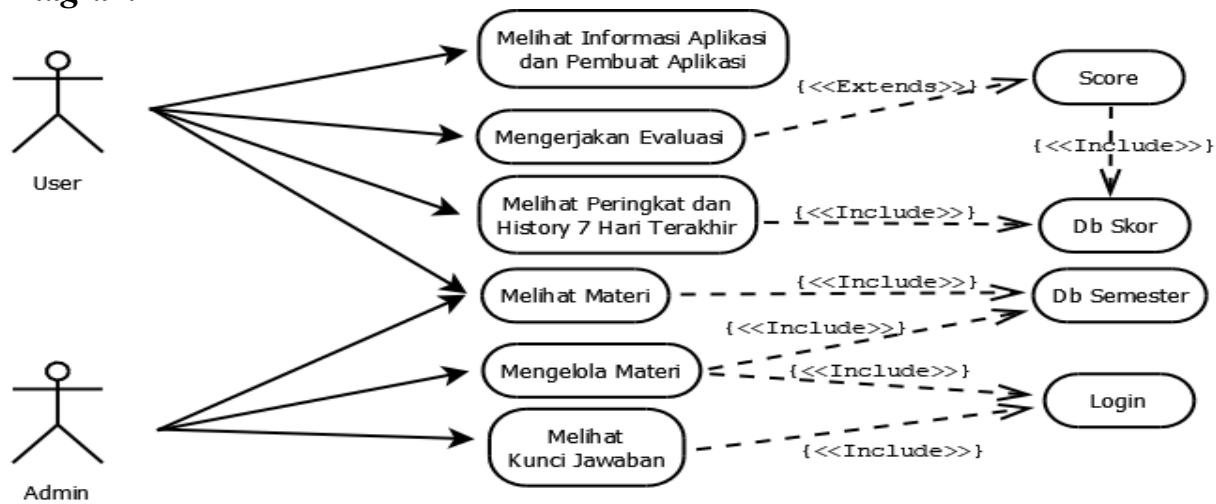

Gambar 2 Uses Case Diagram M-Learning Seni Budaya dan Keterampilan

\section{Tampilan Aplikasi}

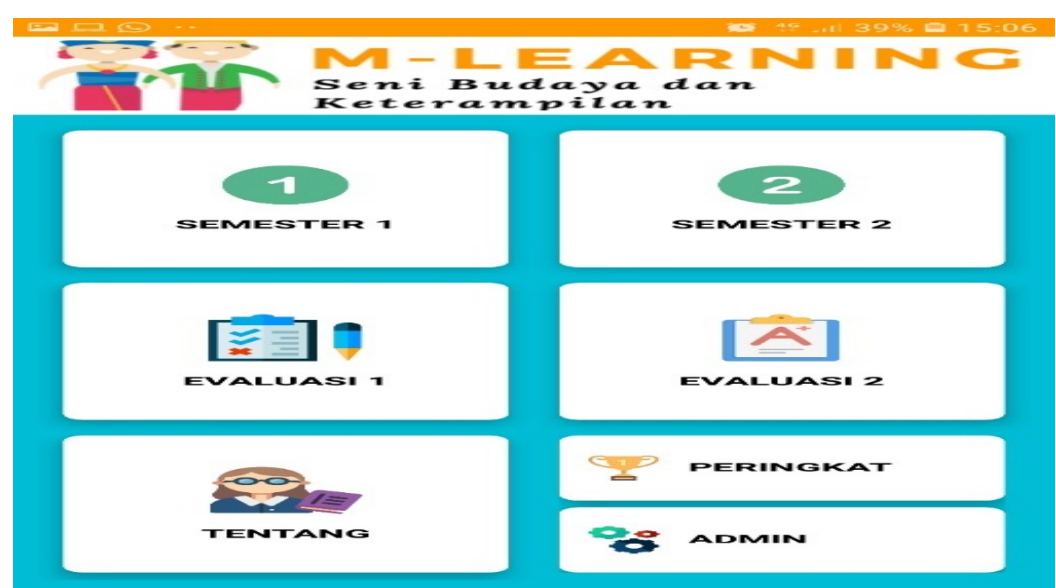

Gambar 3 Tampilan Awal Aplikasi

Menu utama menampilkan 7 pilihan menu, yaitu menu Semester 1, menu Semester 2, menu Evaluasi 1, menu Evaluasi 2, menu Tentang, menu Peringkat dan menu Admin. Pengguna dapat memilih menu yang disediakan dengan mengklik salah satu menu tersebut. 


\section{Tampilan Menu Semester 1}

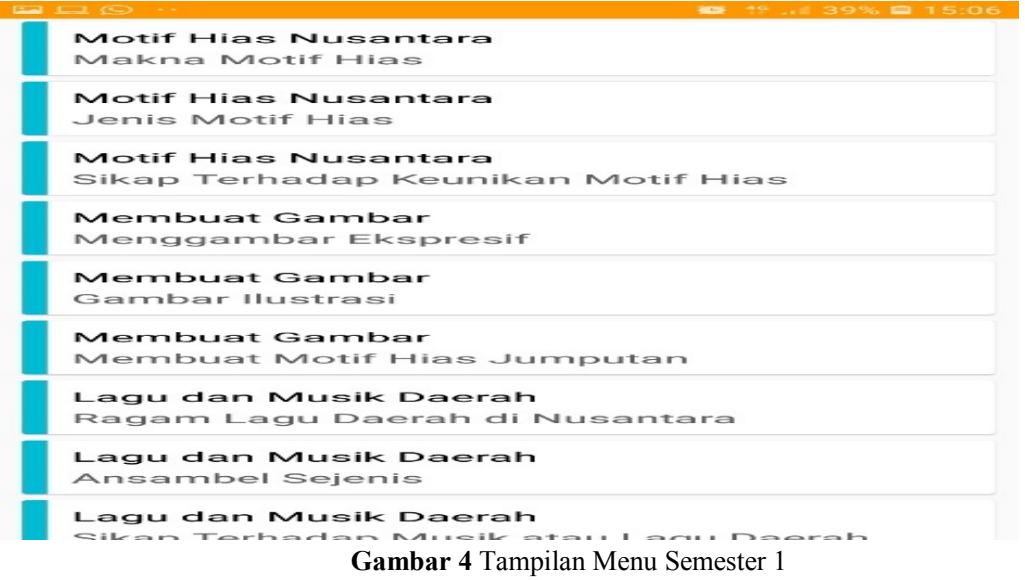

Gambar diatas adalah menu semester 1. User dapat membaca dan belajar materi semester 1 Seni Budaya dan Keterampilan dari menu ini. Materi berupa tulisan yang berasal dari buku Seni Budaya dan Keterampilan kelas 5. Terdapat pilihan materi yang dapat dipilih dan dibaca kapanpun.

\section{Tampilan Evaluasi 1}

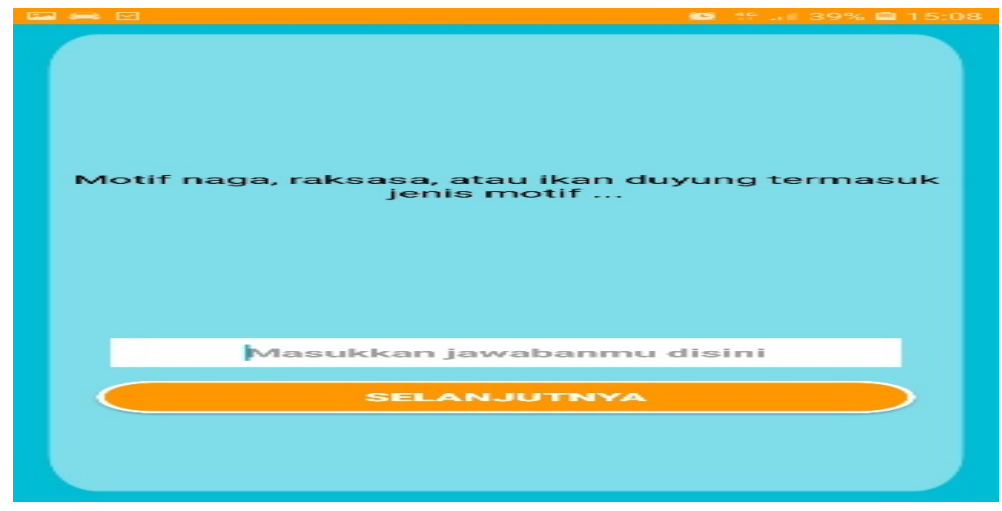

Gambar 5 Tampilan Menu Evaluasi 1

Gambar diatas adalah contoh soal essay pada menu evaluasi 1. User akan diminta mengisi 5 soal essay yang berasal dari materi semester 1 . Apabila sudah selesai mengisi 5 soal essay, maka akan muncul skor pilihan essay. Setelah skor essay muncul, user bisa mengulangi soal atau kembali ke menu utama.

\section{Tampilan Menu Peringkat}

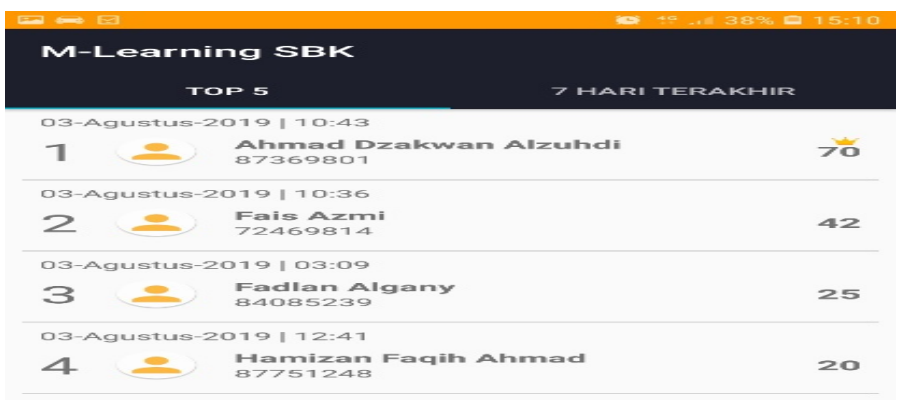


Menu peringkat akan menampilkan TOP 5 hasil evaluasi 1 dan evaluasi 2. Sementara 7 Hari Terakhir akan menampilkan hasil evaluasi 1 dan evaluasi 2 dalam kurun waktu 7 Hari Terakhir.

\section{SIMPULAN}

Dari hasil penelitian yang dilakukan pada perancangan aplikasi M-Learning Seni Budaya dan Keterampilan berbasis android dapat disimpulkan bahwa aplikasi media digital yang telah dirancang dan dibangun dengan tersistem atau terstruktur, dapat mengefisien pembelajaran dan mengatasi keterbatasan penggunaan media buku, memudahkan guru dalam melakukan penilaian kepada murid yang telah mengerjakan evaluasi melalui aplikasi tanpa harus menghitung manual. Dan pembelajaran Seni Budaya dan Keterampilan berbasis Android yang dapat di-install pada smarthphone bersistem operasi android, dapat digunakan di mana saja sehingga membuat murid tertarik untuk mengikuti pelajaran Seni Budaya dan Keterampilan.

\section{DAFTAR PUSTAKA}

Arifin, Z. (2012). Penelitian Pendidikan Metode dan Paradigma Baru. Bandung: PT Remaja Rosdakarya.

Budiman, Tedi. (2018). Perancangan Sistem Pembelajaran Mobile (M-Learning) Berbasis Android Pada Materi Bangun Datar Dan Bangun Ruang. Jurnal Accounting Information System.

Ladjamudin. (2014). Analisis \& Desain Sistem Informasi. yogyakarta: Graha Ilmu.

Liranti Rahmelina. (2017). Perancangan Mobile Leraning Berbasis Android Pada Mata Kuliah Sistem Operasi Di STMIK Indonesia Padang. Jurnal Informatika.

Sugiyono. (2013). Metode Penelitian Kuantitatif dan R \& D. Bnadung: Alfabeta.

Susanto, Azhar. (2004). Sistem Informasi Manajemen konsep dan pengembangannya. Bandung: Lingga Jaya. 